This item was submitted to Loughborough's Research Repository by the author.

Items in Figshare are protected by copyright, with all rights reserved, unless otherwise indicated.

\title{
'The message is the medium': Evaluating the use of visual images to provoke engagement and active learning in politics and international relations lectures
}

\section{PLEASE CITE THE PUBLISHED VERSION}

https://doi.org/10.1177/0263395717717229

\section{PUBLISHER}

(c) The Authors. Published by SAGE Publications (UK and US)

\section{VERSION}

AM (Accepted Manuscript)

\section{PUBLISHER STATEMENT}

This work is made available according to the conditions of the Creative Commons Attribution-NonCommercialNoDerivatives 4.0 International (CC BY-NC-ND 4.0) licence. Full details of this licence are available at: https://creativecommons.org/licenses/by-nc-nd/4.0/

\section{LICENCE}

CC BY-NC-ND 4.0

\section{REPOSITORY RECORD}

Roberts, David. 2019. “'the Message Is the Medium': Evaluating the Use of Visual Images to Provoke Engagement and Active Learning in Politics and International Relations Lectures". figshare. https://hdl.handle.net/2134/24815. 


\section{politics}

\section{The Message Is The Medium': Evaluating The Use Of Visual Images To Provoke Engagement And Active Learning In Politics and International Relations Lectures}

\begin{tabular}{|c|c|}
\hline Journal: & Politics \\
\hline Manuscript ID & PONL-08-16-074.R2 \\
\hline Wiley - Manuscript type: & Learning and Teaching in Politics and International Studies \\
\hline Keywords: & Enagagement, Lectures, Images, Multimedia Learning, Active Learning \\
\hline Thematic Area: & Learning and Teaching \\
\hline Abstract: & $\begin{array}{l}\text { Globalization and digitization have combined to create a 'pictorial turn' that } \\
\text { has transformed communication landscapes. Routine exposure to visual } \\
\text { stimuli has acculturated our students' learning processes long before their } \\
\text { arrival at university. But when they reach us, we expose them to text- } \\
\text { centric teaching out of kilter with the worlds from which they come. More } \\
\text { importantly, emerging scholarship argues that such textual hegemony is } \\
\text { out of kilter with how they learn. This article describes a 3-year } \\
\text { experiment to assess the veracity of such claims. It found that student } \\
\text { academic engagement was greater when apposite images were applied. In } \\
\text { addition, the experiment revealed that introducing imagery triggered active } \\
\text { learning behaviours. The article concludes with a discussion of the } \\
\text { implications of these findings for Politics and International Relations } \\
\text { teaching, and with proposals for diversifying research methods through a } \\
\text { recently-formed Community of Practice. }\end{array}$ \\
\hline
\end{tabular}


'The Message Is The Medium': Evaluating The Use Of Visual Images To Provoke Engagement And Active Learning In Politics and International Relations Lectures.

\section{Abstract}

Globalization and digitization have combined to create a 'pictorial turn' that has transformed communication landscapes. Routine exposure to visual stimuli like images has acculturated our students' learning processes long before their arrival at university. But when they reach us, we expose them to text-centric teaching out of kilter with the worlds from which they come. More importantly, emerging scholarship argues that such textual hegemony is out of kilter with how they learn. This article describes a 3-year experiment to assess the veracity of such claims. It found that student academic engagement was greater when apposite images were applied. In addition, the experiment revealed that introducing imagery triggered active learning behaviours. The article concludes with a discussion of the implications of these findings for Politics and International Relations teaching, and with proposals for diversifying research methods through a recently-formed Community of Practice.

The message is the medium; Engagement; Active Learning; Multimedia Learning; Images; Lectures; PowerPoint. 


\section{'The Message Is The Medium': Evaluating The Use Of Images To Provoke Engagement And Active Learning In Politics and International Relations Lectures. ${ }^{1}$}

\section{Introduction}

This article is concerned with the effect of the use of images in large group lectures on engagement and active learning. Whilst emerging Multimedia Learning scholarship has theorised substantial - even dramatic - increases in engagement and understanding when apposite images are introduced in university teaching, no empirical research has until now tested this hypothesis in any discipline. This article reviews that scholarship and applies a longitudinal control-group research exercise to the hypothesis by conducting research with undergraduate students studying Politics, International Relations and affiliated subjects over a period of three years. The experiment yielded noteworthy results for levels of engagement, but also prompted further research and data showing a marked increase in the presence of active learning practices. It also yielded unanticipated results for neurostandard/dyslexic students

Rise of the visual

In the last two decades, as walls and polities tumbled from Europe to Africa, and as digitization transformed communications, new digital capture abilities on cameras and phones that needed no 'film' shortened the journey from snap to scrapbook.

Simultaneously, the range of material exposed to our lenses has expanded as more people accessed more places than ever before, digitally recording them as they went. The static scrapbooks of old were replaced by mobile social media like Facebook that redistribute billions of images and expose them to millions in just moments. Production and consumption of digital imagery is now virtually unlimited. Like Felten (2008), Curtis (2013) maintains that a crucial turn towards visuality is well underway. People have greater access to cheaper digital recording and projection (free websites, for example) than ever before, and more spaces are evolving to contain and represent them. By 2013 Facebook alone was absorbing 300 million images per day (Cuthbertson, Furseth and Ezell, 2015: 158). Digital databanks marketing millions of images, like Shutterstock and 123RF proliferate, making accessible an ever-growing repository of the visual. Moving images in the form of films and TV mini-series, sports contests and pornography are projected and consumed in most parts of the world with reliable wireless reception (Mitchell, 2002; McStay, 2013; King, 2016). There has never been a more visual time for human beings (Goldfarb, 2002). This is the era in which visual media have become 'the main means of communication and expression in postmodern culture (Tietje and Cresap, 2005). Universities in general face 'the most visual of all learning cohorts' (Coats, 2006: 126).

\footnotetext{
${ }^{1}$ The title was inspired by Marshall McLuhan's celebrated aphorism, 'the medium is the message'.
} 
Colleagues in Politics and International Relations (PIR) have been quick off the mark. Cynthia Weber, for example, wrote that information in the visual era may be 'expressed less through words (although these can be visual) than through still, moving, and multiplying media (photography, film, web-based windows)' (2008: 138). Jack Holland refers us to a multimodality of learning, and was inspired to develop and experiment with visual pedagogies in part because 'more higher education teachers [now] make use of clips, episodes and even entire [TV] series as part of their modules and programs' (2016: 173). His research showed that as part of scheduled teaching programmes, there was a role for moving images (in this case, The West Wing) as a means to the ends of developing critical evaluative skills, and for developing visual literacy. He's not alone: The US miniseries 'The Wire' is the subject of an edited volume (Deylami and Havercroft, 2017). Holland's research was framed intellectually by earlier scholarship proposing that the use of video can increase student stimulation and interest in PIR (Weber, 2001; Weldes, 2003). Holland acknowledges the cognitive dimension to such a process when he refers briefly to work that has identified the brain's 'core intelligences' to create an 'affective' process that potentially offers substantial benefits for trying to understand and learn matters of PIR and indeed other cognate areas. This work stands alone, but it was not located in a wider pedagogic framework that considers, for example, cognition and the visual.

Safia Swimelar also interrogates the notion of the visual in teaching PIR (2013). She is particularly concerned with the use of images and film in teaching human rights and directs her study towards how people's reactions to matters of PIR are influenced and shaped by imagery. Her later work focuses more on film and its application to specific areas of IR like media and human rights, and this drift towards moving images and specificity is mirrored in the work of other PIR scholars (Simpson and Kaussler, 2009; Kuzma and Haney, 2001). Their shared concern is that of a critical examination of whether and how video supports teaching and learning in certain areas of PIR. Similarly, Brandon Valeriano (2013) investigated the delivery of elements of a module in Politics though film. Again, however, whilst the work stands alone, it has not been set in the wider content of scholarship that considers visuality as a pedagogic medium in its own right, alongside textuality.

Weber's research on visual pedagogies, however, is concerned with questions of power and hegemony. It interrogates the question of why visual language is relegated so far behind textual language, when the world that is the subject of PIR scholarship was increasingly presented, disseminated and consumed in visual form, and when we are all visual learners by virtue of our sightedness. Like Swimelar, Holland and others, she imagined a matching of technological modernity and pedagogic method in teaching, where there was at least some kind of balance in the use of text and images. Unlike her counterparts, she was concerned more with the ways in which mainstream, conservative, textual, 'linguistic' PIR had 'ex-communicated' visuality and delegitimated it in the process (2008: 138). Grayson (2008: 394) has remarked on PIR's historical tendency to act as a 'gatekeeper' of 
permissible debate and knowledge; in that intellectual domain, language remains paradigmatic for meaning (Mitchell, 1994). Thomas et al (2008: 23) add that alternatives and complements in the form of images, for example, are considered to 'simply entertain or illustrate, providing a respite from serious academic work'. This means, for Deandra Little, Peter Felten (2010: 44) that, 'visual literacy continues to be marginalized in... liberal education'. In this process of exclusion, a potentially very effective tool of communication that is expanding all the time in reach, subject coverage, reliability, versatility, popularity and accessibility and is part of our students' life-worlds before, during and after university, was effectively jettisoned without proper or reasonable critical examination. Given the undeniably visual range and scope of the digital world, the ways the subject matter of PIR lend themselves to visual reproduction and dissemination, and the extent to which the world our students study is conveyed to them visually, then to cite Grayson (2015: 161), it would seem 'amiss to omit it from the teaching of international relations'.

The above scholarship reveals some important issues and/or omissions that serve as the point of departure for this article. First, other than for Weber, the idea of visual language or communication is viewed as an addendum in teaching - as a supplemental and/or supporting role for the primacy of text. Weber's is the only work surveyed that touches on the possibility that visual language might represent as constitutive a pedagogy as text is in the teaching of PIR. This article elaborates and asks a similar question, but from an MML perspective (below), as its starting point. Second, there is no sustained engagement in the surveyed literature with well-established MML scholarship on multimodal ways of learning. Holland briefly identifies Mayer but doesn't engage with the substantial research at hand. It is from this linking literature that this article proceeds, with the intention of contributing to the debate on how we might better teach and engage PIR students in ways best suited to their physiological abilities and the techno- social contexts from which they come.

\section{Multimedia Learning (MML)}

At the heart of Multimedia Learning (MML) research is the proposition that 'people can learn more deeply from words and pictures than from words alone' (Mayer, 2014: 1). There may be a ring of familiarity to this. We are taught that 'a picture paints/is worth a thousand words'. We know that sighted people learn visually from birth until death or sight loss. MML scholarship posits a method that is as valid for PIR teaching as for any other academic discipline. This research (Mayer, 2014; Mayer and Moreno, 1998; Mayer and Sims, 1994) is built on decades of preceding inquiry concerned with mental processing and short-term memory (Paivio, 1971; Paivio, 2014). It tells us that humans possess 'separate systems for processing pictorial and verbal material' (Mayer and Moreno, 2003: 44). Cognate Load Theory (CLT), the basis of much MML research, argues 
that we have auditory-textual and visual-imagery channels that divide and guide information for mental processing, so information processing should be balanced between the two channels (Paivio, 2014; Mayer and Moreno, 2003; Lewis, 2016).

According to this understanding, adherence to text-centricity is bad for students' learning experiences for two reasons. First, excessive text on slides overloads short-term memory processing. Many people find it hard to memorise multiple phone numbers, for example. Such views are not considered radical. Indeed, according to one critic, 'the major theories and models guiding [that] research are well accepted and based on classical memory research' (Ayres, 2015: 634; Sorden, 2013; Lewis, 2016). Second, reliance on text wastes the potential sighted people have to explore, interpret and engage the world through images - what they do as a matter of course beyond the lecture theatre. The pedagogic effect of overreliance on the 'linguistic turn' is likely familiar to many of us in the form of 'Death by PowerPoint' in PIR lectures and quite probably in most disciplines in most colleges and universities. It is present in industries worldwide, leading social commentators and scholars to disparage and belittle PowerPoint (Tufte, 2015; Kosslyn, 2007; Bumiller, 2010; Gaskins, 2012; Kernbach, Bresciani and Eppler, 2015; Thompson, 2003). But we should be careful not to eject babies and bathwater. Helping the linguistic turn develop in line with social evolution requires the informed integration of imagery, and PowerPoint is admirably suited for just that. We wouldn't blame Microsoft Word for a bad article. It becomes a matter of recognizing that the familiar PowerPoint software is well-suited to support efforts to map and optimize how we teach to how we learn. Imagery in Weber's three forms (above) becomes in this envisioning a constitutive pedagogic element that enables (teaching) delivery to reflect (learning) capacity.

This is a challenging perspective. It would be easy to conclude that we are being told by MML research that we need to radically transform how we teach and that we need to dispense with text, which would raise a mass of legitimate questions about how an image could provide the entire technical content of, say, the US Constitution or the Universal Declaration of Human Rights. It is not suggesting this. It is proposing we might be open to considering a better balance of academic content delivery, divided between our ears and our eyes. It does not mean all we should deliver is imagery. It does not suggest text should only be a bare minimum. It does not mean we should have images on every slide. It posits that we will learn better if we stop overloading one means of learning and under-using another. It is an argument for balance. MML establishes a physiological rationale for the use of images. It argues that the use of images and text is better than the use of text alone. It predicts that using images and text, instead of text alone, will increase student engagement with academic material. This claim is the basis for the following experiment. 
But during the experiments, it became clear that students were also engaged in active learning processes, an outcome not predicted by MML scholarship. The following account of a three-year experiment elaborates on both engagement and active learning.

\section{Lecturing with images and text ${ }^{2}$}

For three years (2013-2016), Loughborough university has been using full-slide (integrated as the background to a slide), high-quality (bigger than $800 \times 600$ pixels), still images (photographs, oil paintings, Photoshop, film stills, 3D renditions) in lectures in PIR and associated sub-arenas, including third world politics, peace and conflict studies and international history. Starting in 2013, PowerPoint lecture slides used full-slide images with reduced text or text relocated to PowerPoint's 'notes view'. From the outset of introducing images, it became clear that a taxonomy is needed to discuss the visual pedagogy involved. The images used in these lectures can be classified as literal (or representative); metaphorical (or figurative), and paradoxical, which can straddle both.

Literal/representative images are the simplest. For example, if discussing the EU, we may use an image of the EU flag. But we may also wish to discuss how the EU is represented in other ways. One such conversation is facilitated in Figure 1.

Figure 1 EU flag barbed wire

This transforms the EU flag into something that integrates the values of the EU as it is normally considered, with the notion of containment, imprisonment, or exclusion. This image builds on students existing knowledges (of the role of the EU as a facilitator of regional prosperity, and then confuses that knowledge by implying something is wrong in adding barbed wire. In one interpretation, the clash between the two dimensions forces an attempt to reconcile the apparent contradiction; the components of the image are disaggregated and interrogated. New knowledge arises as students connect the EU to exclusion politics in contemporary scenes of migration.

But in addition, when academic subject matter is alien to students, literal images can describe what students may never have seen. One example used is of desertification.

\footnotetext{
${ }^{2}$ A note on finding images. A first port of call might be Google Advanced Image Search, which has a copyright filter. DeviantArt members will often give written permission for specific high-value images. Unsplash.com and Pixabay.com provide some free material also, and university libraries often provide access to (limited) external databases. Schools can also buy low-cost subscriptions through places like Shutterstock, 123RF and Depositphotos. The cost is low because the licence we need to use them for education is not considered high-value by the market.
} 
Figure 2 Desertification

Images like this one may bring otherwise unfamiliar places, concepts and practices to life in ways that text alone does not. One student in the lecture remarked afterwards that she had heard of the term (desertification) but had never paused to consider it, and was now interested in its causes because she could see what it looked like in her own world. The image has both added and subtracted in this pedagogic process: added another means of communication and exploited visual processing, and subtracted the textual method that overloads mental processing capacity.

A second category is the visual metaphor. These have a long and rich history as a means of rendering familiar the unfamiliar (Aldrich, 1968; Serig, 2006). Eppler (2006: 203) argues that visual metaphors involve 'a graphic structure that uses the shape and elements of a familiar natural or manmade artefact or of an easily recognizable activity or story to organize content meaningfully and use the associations with the metaphor to convey additional meaning about the content'. Williams (1998: 3) suggests that for teaching, a visual metaphor 'should be appropriately simple enough to be easily interpreted, but include enough detail so that the learner can process the metaphor quickly'. They are usually more complex than illustrative images and deliver more of a message. According to Edward McQuarrie and David Mick (1999), when metaphorical images are easily recognizable, engagement is more active and intense and may evoke more complex cognitive processing than literal images can. Put differently, visual metaphors 'support learners in connecting what they already know (the properties of the metaphor domain) with new material (the domain onto which the metaphor is being applied)' (Eppler, 2006: 206). The following are some examples of metaphor images used in a variety of Politics and International Relations lectures over three years.

Figure 3 Evolution, by Kiciak, above

Reproduced with written permission of the artist Christophe Kiciak, http://www.kiciak.fr/p77750736\#h288fa048

This image appeared as part of a lecture that looked at Realism and Constructivism. It supported a discussion of innate biological determinism and was accompanied by one that instead. Another image supported a discussion of tensions between Liberal and critical feminisms over the politics of pole dancing. The image's component parts present pole dancing not simply with the autonomous sexuality and free choice it is claimed to bring, but also with the privileging of masculine preferences that misrepresent progress for women. 
Figure 5, pole dancing

A third type of image is the paradox image. According to Eliason (1996: 341), a paradox is a statement that may appear to be self-contradictory but which may simultaneously communicate a truth Paradox images may present as puzzles, creating temporary confusion generating internal attempts at reconciling meaning. A well-known example is the eternal triangle. This diamond with blood

Figure 8 Blood diamond

is a useful example. A diamond is normally a symbol of betrothal, or a gift marking something positive. Such constructs are not immediately associated with blood or bodily destruction until we examine subjects like domestic violence, honour killing, dowry murder and so on. This image was also used to support a discussion of capitalism and conflict ('blood/conflict diamonds'). It was also used to discuss hypermasculinity and intimate partner killing globally. Presenting two opposing, conflicting concepts simultaneously can structure engagement and interrogation through curiosity and confusion, according to focus group research undertaken here (below).

Another image I use helps me discuss war and peace. I wanted to convey the idea that despite being a very attractive proposition for many, the idea of 'peace' in much literature is seen as fanciful, in the face of hegemonic 'realities' and ideologies that legitimate war as an inevitability. Peace is discredited by 'reality'; yet reality is for many a construct.

Figure 10 wolf and dove

These are complex subjects involving ontologies, hegemony and exclusion. Yet images are able to support discussion and text to convey meaning and engagement.

\section{Evaluating the method}

For the last three years, all my undergraduate modules have been delivered using a balance of images and text. Approximately three-quarters of the slides use an image of some kind. The remainder of slides are limited to a maximum of two lines of text each. This means there may be more slides than usual; but no more content than usual, taking the same time to deliver. 
Alongside this process, I conducted an experiment to establish the extent to which, and why, the visual method did or did not work as the MML literature hypothesises. The experiment was concerned with 'engagement', an issue presently on many agendas in HE. By 'engagement', I refer to students' engagement with their 'studies and... [with] pedagogic practices'. I do not refer to non-academic engagement with elements of university life such as 'social group or institution' (Gibbs, 2010: 47; Trowler, 2010). To this end, I sought volunteers from my module student body to participate in control/test group evaluation and in focus groups, combining ethically-approved quantitative and qualitative approaches. The quantitative approach mirrors the established research methods of Chanlin (1998), McKay (1999) and Kleinman and Dwyer (1999), who conducted similar comparative research regarding moving imagery. I adapted their approach and created two randomized control and test groups from the student volunteers. Neither group exceeded 15 students. Gender division averaged 66\% male, $34 \%$ female, all participants were between 18 and 21.

Each group was exposed to a 10-minute presentation in a lecture theatre on global warming (the topic was chosen for its broad familiarity in Politics and International Relations). The control group received the presentation using text alone. The test group was exposed to the same academic content delivered with images and text. No other variable changed. Immediately after the presentation, each participant completed a Bristol Online Survey (BOS). They were asked to indicate the extent to which they agreed with the statements appearing on the graph (Figure 1). Those exposed to text appear as blue, and those exposed to images and text appear as yellow. The test was repeated six times over three years (once each semester). The table below aggregates the quantitative data for all three years

\section{Table 1 Engagement aggregated 2014-2016}

Students exposed to images ${ }^{1}$ declared greater cognitive and emotional engagement. Emotional engagement is here presented as learning is that which happens when a student develops a personal interest in academic content leading to and/or deriving from neurobiological 'activations all around the cortex, in regions involved in cognition, memory and meaning-making, and even all the way down into the brain stem' (Immordino-Yang, 2015: 27). A higher proportion of students in group 2 than in group 1 agreed that the slides encouraged them to think about the material being presented, to understand it and to be stimulated emotionally by it. In these conditions, the extent to 
which image-based slides encouraged study-related engagement (Gibbs, 2014; Trowler, 2010) exceeded substantially the extent to which slides with text-only achieved engagement.

\section{Focus group testing, academic engagement}

Qualitative testing using focus groups was conducted to explain the quantitative outcome. Groups consisted of six or seven students, with normally more males than females in similar proportions to the quantitative testing. The approach was semi-structured and encouraged students to discuss with each other what was happening for them during image-based presentations. They drew from their experiences of having been exposed to this method of teaching in the line of their regular modules (all lectures delivered by this author use image-based slides). The evidence presented below is an amalgam of all the focus groups over all three years.

Students in these focus groups were unanimous in stating that the images helped them engage with the material more than text did. Literal images 'displayed' the subject and 'made it real' and 'come to life'. They didn't want to 'just copy stuff down' because they 'didn't need to come to lectures to do that' because the same text was already on the Learn platform. The literal images 'drew' them into the subject; 'I could roam around the images and still hear everything you said and be interested. I had a little journey with each image'. They were clear, however, that images had to be apposite, reflecting Bartscha and Cobern's (2003) conclusions regarding the utility of images in teaching. But it also became clear that their value in relation to metaphor and paradox images was relative. They claimed that the two types (literal and figurative) did two different things for them, of different value. Whilst both prompted engagement as Gibbs and Trowler have enunciated it, metaphor and paradox images prompted spontaneous critical engagement, because those images 'troubled' or 'destabilized' them by presenting a conundrum that made them 'intrigued' as to the meaning of the image. Metaphors and paradoxes demand interrogation for their resolution; they are not there to create a straightforward impression or answer. They are often made of opposing elements (blood/diamond). The tension between component parts of the images provoked internal confusion that their minds 'automatically' attempted to reconcile because the metaphor and paradox images didn't initially make sense. Students said they found themselves 'concentrating much more'. One said she was 'stung' into working out what the image meant because it made no sense on initial inspection.

If engagement with academic study includes the desirability of attending lectures, 2 students claimed that the images made no difference to their attendance, because they attended all lectures regardless of their format. But across all the focus groups over all 3 
years, the view was that the use of large images and reduced text made them 'look forward to the whole experience', adding that 'there is too much to miss' in an imagebased lecture. They identified a 'novelty factor' because this method was different from their other experiences of lectures, an element that would disappear if the method were widely applied.

Some students were concerned that the images provoked conflict in the form of argument or debate. They noted that some images could be viewed as controversial, citing one that appeared to explain support for the attacks on 9-11, found on a wall in Lebanon. This image had generated debate off-campus in the weeks following its use; but it was not the only one that had this effect. The blood diamond example was similarly cited as provoking debate and stimulating argument. One student declared in university correspondence that he would never think the same again about buying a ring when he got married. They concluded that, on balance, if something in a lecture had this effect, it was probably a good thing because the images clearly held their attention during and after the lecture.

There were some specific thoughts raised in the focus groups that give a clearer picture of what is happening for them in this visual process, and they bear considering in a little more depth. The MML scholarship makes a distinction between text and images, arguing for a rebalancing from text domination (Lewis, 2016; McKay, 1999; Mayer and Moreno, 2003). Students exposed to the visual method were asked about the effect the rebalancing had on them. One referred to the use of images from Tu Do hospital, of mutagenic children who biologically inherited their condition from the use of Agent Orange in the American War in Viet Nam. He remarked that 'there's a big difference between hearing about this and seeing it. Words on their own bring a subject to our attention. But "mutagenic" meant nothing; it sounded like a Marvel comic thing. If I hadn't seen what it entailed, I would have just skipped on. There's before that image and there's after it'. He added that the image made him 'connect' with the subject whereas words informed but 'couldn't engage like those images can'. He said that he was 'interested in why this happened and what was being done about it'.

Focus group members also considered how images affected their attendance at lectures. They said they found it hard to concentrate in 2 hour blocks, unless they were punctuated with diversity in the way teaching and learning was delivered. However, most of their lectures were text-only, with a break at half-time. One said 'people leave at half time. I haven't seen that in one of [these] lectures so far. He then made a remark that may be familiar to people who flew Aeroflot in the past, who may recall that passengers clapped when the pilot made a safe landing, however dire the whole experience was. 'These 
lectures get a round of applause. To be fair, people clap in other lectures, but that's more because they're finished'.

Students were asked to reflect on the change in dynamic from text to imagery, as opposed to the effect of images. A minority were unaware that the usual text appeared in the 'notes view' area of PowerPoint and were worried they would have nothing to revise from. With this not being the case, they discussed the effect of losing visible text. The first thing they all commented on was that they could now listen properly, instead of dividing their attention between slides and speaker, both of which often bore close parallel. Some lecturers still read the slides aloud, which appeared to be the most annoying concern. MML and Cognate Load Theory posits that this is a harmful process because it overloads short-term memory and underexploits powerful visual processing capacities (Lewis, 2016; Mayer and Moreno, 2003). The students concurred, saying in one instance that reading and listening to the same thing reminded him of 'trying to watch a foreign language movie and needing to read the subtitles'. He couldn't do both effectively. He added: 'when I'm listening to a voice and seeing a picture, I'm not scribbling down the slide text we get anyway on Learn... Listening to someone read aloud the same thing I'm reading is impossible for me'.

Text-heavy slides were 'like garlic to a vampire'. One declared that he would 'give up' when confronted with text-filled slides. To broad concurrence, he said:

I have to make a choice. Am I going to listen to the lecturer, or am I going to read the text he's providing? Half of a lecture is wasted if I have to choose. I can't read the text and listen as well. [Privileging] images, the words complement the image or the image complements the words, instead of me having to pick or choose.

\section{Active Learning}

The data derived from these focus groups inspired a new line of inquiry regarding the role of images in the generation of active learning processes. I was especially interested in this unexpected outcome because scholars of pedagogy have long been concerned with the passive reception of knowledge in HE lecture settings. Such relations of dominance derive (in part) from the idea that a lecturer held knowledge and imparted it to his or her students for them to receive and reproduce uncritically (Haidet et al., 2004; Beetham and Sharpe, 2013). Critics have long charged that such passivity is the opposite of what we wish to achieve in $\mathrm{HE}$ : independent, autonomous agents able effectively to engage critically with a rapidly-changing world. This, it is argued, requires active learning, whereby it is recognised that students are not blank slates but carry with them their own 
knowledges and perspectives that can build on and/or reshape taught knowledge. In this view, the 'sage on the stage' is replaced with 'the guide on the side' (McWilliam, 2008; Cantillon, 2003). Active Learning (AL) is increasingly seen as a desirable path along which to advance pedagogy in $\mathrm{HE}$.

AL comprises several characteristics. For example, Michael Prince (2004: 223) identifies 'meaningful learning activities' which prompt students to 'think about what they are doing'. This might involve a problem to be solved by students (Savery, 2006; Torp and Sage, 2002). Problem-solving will 'force [learners] to reflect upon ideas and how they are using those ideas... through activities that involve them in gathering information, thinking, and problem solving' (Michael, 2006: 160). Similarly, Michael Winterbottom (2016) describes active learning as

posing scientific questions, analyzing evidence, connecting such evidence to pre-existing theoretical knowledge... Learners replace or adapt their existing knowledge and understanding (based on their prior knowledge) with deeper and more skilled levels of understanding.

It is argued that the act of stimulating inquiry generates involvement. Levy (2012: 17) maintains that 'students' engagement with an inquiry process... drives their activity'.

AL broadly encompasses a range of approaches including Inquiry-Guided Learning (IGL). IGL presents as a 'cluster of related instructional approaches in which student inquiry or research drives the student experience of learning and participation in knowledge building' (Levy, 2012: 18). Levy (2012: 17) presents examples in the form of 'intriguing fieldwork or design problems, real-world themes generated by external agencies or arising out of professional practice, complex case scenarios, stimuli such as visual resources, or simply open research questions'. Common to much AL pedagogy, then, is the idea of interrogation of subject matter, presented in whatever form, including visually. There is also the idea that existing knowledge is built on by students and lecturers together, instead of all lecture-dispensed knowledge being new and decontextualized. For the purposes of this study, AL here refers to the presence, in a live traditional lecture environment, of student engagement with lecture content that involves the presentation of problems that result in live student efforts to make sense of and search for a solution to those problems, drawing at least in part on their existing knowledges. This representation of $A L$ reflects key characteristics identified by leading scholars of this pedagogy (Torp and Sage, 2002; Savery, 2006; Prince, 2004; Michael, 2006; Levy, 2012). This definition formed the basis of questions asked in control/test group and focus group settings. 
The objective of the second study conducted in 2015 and 2016 was to establish the extent to which students considered that these dimensions of AL were present in text-only, and image and text based slides. The research method remained the same. This series of control/test group quantitative experiments produced a pattern similar to that observed in regard to engagement. Group 1 (blue) was exposed to text-centric slides. Group 2 (yellow) was exposed to image-centric slides with limited text. The use of images predicts the presence of active learning in this study.

Table 2 Active Learning aggregated 2015-2016

\section{Focus group testing, active learning}

Focus groups were again engaged to explore some of the quantitative findings. They were all drawn from students exposed to the image-based method during their normal lecture routine. Students were asked what was happening for them as they viewed images in relation to them being active participants in the process. It became clear that, whilst any apposite image was better for them than having a slide full of text, metaphor and paradox images generated more activity. When confronted with an image like the blood/conflict diamond or the ape with human eyes, they were 'puzzled at first'. There was a 'misnomer' or a 'problem with the components of the image' that needed to be 'resolved'. One student said: 'I didn't even realize what I was doing. I was just in the picture, thinking about it whilst you talked'. It is worthwhile including some lengthier quotes to illustrate this.

Interestingly, the problem-solving dynamic appeared to the students to have a mind of its own, or an 'auto-reaction'. The images provoked interrogation because they were 'illogical', 'irrational', 'wrong', 'surprising', 'perplexing' and 'needed to be reconciled'. Students were almost unanimous that images with opposing or conflicting elements mean 'you are working the problem. I really like the problem-solving - what is going on in the image forces you to work it out because it presents a problem'. In another example, of a transparent pill with skulls inside it, one student described what happened as she looked at it and listened to the lecture.

I see the pill and think health, then I see the skulls and I think that's not right. I see the pill and have thoughts about health; I see skulls and have thoughts of death. Then I try to link it with what the lecturer is saying, and it completes a circle and brings it to life. I can then understand more about the morality of Big Pharma charging poor people for life-saving medicine or 
something like that. The confusion the image creates makes me try to reconcile the content, which means I am thinking of explanations myself whilst the lecturer is talking around it. I am asking, why is there an image that's created like that? It goes against what I thought I knew, what I'd been told, what I'd learned before.

Active learning is in part characterized by students building on existing knowledge and reforming and evaluating it as new knowledge is added. According to Eppler (2006: 206), a metaphorical image 'activates prior knowledge' and challenges students to assemble the elements logically in order to arrive at a conclusion of meaning (Dent-Read, Klein and Eggleston R. , 1994). Students seeing images 'make linkages and build on them'. One student elaborated regarding an image referring to the Cold War:

It makes me think: what did I know about the Cold War? How does the image relate to the Cold War? What have I learned now about the Cold War? Why does this image work with the Cold War? I come to my own answers in parallel with the lecturer's comments. I'm half the deal. I'm not just sitting silently on 'receive', I'm working to understand, using my brain to ask questions. It's almost the opposite of a normal lecture.

She went on to add that

This is a case of 'image content challeng[ing] our pre-conceived ideas, forc[ing] us to question what we came to the lecture with. It helps you think more critically. With images, you're thinking about them all the time, rather than just reciting learning from the slide. The [Cold War] image forced me to question what I already knew and draw a different conclusion from it. I was learning for myself instead of being taught to.

A second year undergraduate remarked thus:

I start not knowing what the image is. Watching a confusing image makes me want to hear what the lecturer has to say about it. I need to work the image out, whereas if it's just text I'm bored. I don't need to work anything out; I just rewrite what I'm being shown on the slides. Being confused like that keeps you stimulated the whole lecture, especially since we know there will 
be more images like this and more puzzles to understand. It keeps us on our toes.

The focus groups concluded thus: 'images up the ante and give me autonomy, make me active in the lecture, instead of text that spoon-feeds me'. The view was unanimous in each focus group in each year. One student said, 'if your brain is engaged enough to be asking, "what is that?", then you are definitely active in the learning process. I'm involved in these lectures. I'm busy'.

\section{Additional evidence and wider applications.}

This data is heavily dependent on students, partly because students have been conspicuously absent from assessments of student engagement (Trowler, 2010). There is, however, some evidence of intellectual improvement. In two PIR modules using this method, the percentage of externally-validated coursework 'firsts' rose from 10-30 between 2013 and 2016. 2013 is the baseline before the visual method was used. This on its own is scarcely rigorous or sustained but it mirrors the other data presented here, and the presentation of such information at School Open Days to our students' families using the visual method has elicited a variety of anecdotal data that show meaningful support for the method from our students' parents.

\section{Conclusion}

Large group, text-centric lectures remain the hegemonic method of learning and teaching delivery in neoliberal $\mathrm{HE}$, despite concerns that this approach is pedagogically harmful, disengages students and provides primarily passive learning ill-suited for student and employer needs in the third millennium. But MML research hypothesizes that this can be changed by recognizing imagery as a constitutive pedagogy with merit equivalent to text. This is because incorporation of imagery in lectures reduces cognitive stress caused by text overburdening and exploits under-used visual processing capacity present for all sighted people. This research aimed at establishing the effect of apposite images on PIR student engagement with academic content, and found a substantial increase among those exposed to apposite images and text. It also found that apposite images provoke the key constitutive elements of Active Learning, a process considered by many to be in short supply in the large group lectures common to neoliberal educational paradigms. However, three valuable qualifications became clear. First, apposite images that convey relevant meaning, even if only descriptive, serve the dual purpose of exploiting visual processing whilst reducing the harmful effects of excessive text understood well in the MML literature. They both add value and subtract harm. Second, metaphor and paradox images that are not immediately comprehendible induce active student interrogation. 
Third, engagement through metaphor and paradox images incites problem-solving behaviours and the co-production of knowledge, per the characteristics of AL.

This research is in the early stages. It has been widened to other disciplines beyond PIR with similar results and is being tested in natural science academic environments. A 16university international Community of Practice is evolving to assess, amongst other things, whether the method produces similar results with other demographics and whether it works in postgraduate and seminar settings. A method of testing for prefrontal cortex (engagement) activity using frequency Near Infrared (fNIR) scoping is under development.

Visual media are normally welcomed by our students when we use them, and are increasingly being used by teaching colleagues to vary delivery. This research affirms and formalizes the clear pedagogic value of images, despite the resistance of some orthodox elements in the discipline to such innovative pedagogies. Perhaps the clearest message this research can present is that the message is the medium, to paraphrase Marshall McLuhan. 


\section{References}

Aldrich, V. (1968) 'Visual Metaphor', Journal of Aesthetic Education, vol. 2, no. 1, pp. 73-86.

Ayres, P. (2015) 'State-of-the-Art Research into Multimedia Learning: A Commentary on Mayer's Handbook of Multimedia Learning', Applied Cognitive Psychology, vol. 29, no. 4, pp. 631-636.

Bartscha, R. and Cobern, K.M. (2003) 'Effectiveness of PowerPoint presentations in lectures', Computers \& Education, vol. 41, pp. 77-86.

Beetham, H. and Sharpe, R. (2013) Rethinking Pedagogy for a Digital Age: Designing and Delivering E-learning, London: Routledge.

Bumiller, E. (2010) We have met the enemy and he is PowerPoint, 26 April, [Online], Available: http://www.nytimes.com/2010/04/27/world/27powerpoint.html [12 April 2017].

Cantillon, P. (2003) 'Teaching large groups', British Medical Journal, vol. 326, p. 437.

Chanlin, L. (1998) 'Animation to teach students of differing knwledge levels', Journal of Instructional Psychology, vol. 25, no. 3, pp. 166-175.

Coats, J. (2006) Generational learning styles, River Falls, Wisconsin: LERN.

Curtis, N. (2013) The Pictorial Turn, London: Routledge.

Cuthbertson, R., Furseth, P.I. and Ezell, S.J. (2015) Innovating in a Service-Driven Economy: insights, application and practice, London: Palgrave Macmillan.

Dent-Read, C., Klein , G. and Eggleston R. , G. (1994) 'Metaphor in visual displays designed to guide action', Metaphor and Symbolic Activity, vol. 9, no. 3, pp. 211-232.

Deylami, S. and Havercroft, J. (2017) The Politics of HBO's The Wire: Everything is Connected, London: Routledge.

Eliason, J. (1996) 'Using paradoxes to teach critical thinking in science', Journal of College Science Teaching, vol. 25, no. 5, pp. 341-344.

Eppler, M. (2006) 'A comparison between concept maps, mind maps, conceptual diagrams, and visual metaphors as complementary tools for knowledge construction and sharing', Information Visualization, vol. 5, no. 3, pp. 202-210.

Felten, P. (2008) 'Visual Literacy', Change: The Magazine of Higher Learning, vol. 40, no. 6, pp. 60-64.

Gaskins, R. (2012) Sweating Bullets: Notes about Inventing PowerPoint, New York: Vinland Books.

Gibbs, G. (2010) Dimensions of Quality, York: Higher Education Academy.

Gibbs, G. (2014) 'Student engagement, the latest buzzword', Times Higher Education, 1 May, Available: https://www.timeshighereducation.com/news/student-engagement-the-latestbuzzword/2012947.article.

Goldfarb, B. (2002) Visual Pedagogy: Media Cultures in and beyond the Classroom, Durham (US): Duke University Press.

Grayson, K. (2008) 'Human security as power/knowledge: the biopolitics of a defintional debate', Cambridge Review of International Affairs, vol. 21, no. 3, pp. 383-401. 
Grayson, K. (2015) 'The Challenges of Teaching Popular Culture and World Politics', in Caso, F. and Hamilton, C. Popular Culture and World Politics, London: E-International Relations, Available: http://www.e-ir.info/wp-content/uploads/2015/04/Pop-Culture-and-World-Politics-E-IR.pdf.

Haidet, P., Morgan, R.O., O'Malley, K. and Jeane, B. (2004) 'A Controlled Trial of Active Versus Passive Learning Strategies in a Large Group Setting', Advances in Health Sciences Education, vol. 9, no. 1 , pp. 15-27.

Holland, J. (2016) 'Visual Literacy in International Relations: Teaching Critical Evaluative Skills though Fictional Television', International Studies Perspectives, vol. 17, no. 2, pp. 173-186.

Immordino-Yang, M. (2015) Emotions, Learning, and the Brain: Exploring the educational implications of Affective Neuroscience, New York: WW Norton \& Co.

Kernbach, S., Bresciani, and Eppler, M.J. (2015) 'Slip-Sliding-Away: A Review of the Literature on the Constraining Qualities of PowerPoint', Business and Professional Communication Quarterly, vol. 78, no. 3, pp. 292-313.

King, F. (2016) 'Visual approaches to property law pedagogy', International Journal of Law in the Built Environment, vol. 8, no. 1, pp. 80-94.

Kleinman, E. and Dwyer, F.M. (1999) 'Analysis of computerized visual skills: relationships to intellectual skills and achievement', International Journal of Instructional Media, vol. 26, no. 1, pp. 53-69.

Kosslyn, S. (2007) Clear and to the Point : 8 Psychological Principles for Compelling, New York: Oxford University Press.

Kuzma, L. and Haney, P.J. (2001) 'And... Action! Using Film to Learn about Foreign Policy', International Studies Perspectives, vol. 2, no. 1, pp. 33-50.

Levy, P. (2012) 'Developing inquiry-guided learning in a research university in the United Kingdom', in Lee, V. Inquiry as a Way of Learning in Undergraduate Education. New Directions for Teaching and Learning, San Francisco, CA: Jossey Bass.

Lewis, P. (2016) 'Brain Friendly Teaching-Reducing Learner's Cognitive Load', Academic Radiology, vol. 23 , no. 7, pp. 877-880.

Little, D., Felten, P. and Berry, C. (2010) 'Liberal Education in a Visual World', Liberal Education, vol. 96, no. 2 , pp. 44-49.

Mayer, R. (2014) The Cambridge Handbook of Multimedia Learning, $2^{\text {nd }}$ edition, New York: Cambridge University Press.

Mayer, R. and Moreno, R. (1998) 'A split-attention effect in multimedia learning: Evidence for dual processing systems in working memory', Journal of Educational Psychology, vol. 90, no. 2, pp. 312320.

Mayer, R. and Moreno, M. (2003) 'Nine Ways to Reduce Cognitive Load in Multimedia Learning', Educational Psychologist, vol. 38, no. 1, pp. 43-52.

Mayer, R. and Sims, V.K. (1994) 'For whom is a picture worth a thousand words? Extensions of a dual-coding theory of multimedia learning.', Journal of Educational Psychology, vol. 86, no. 3, pp. 389-401. 
McKay, E. (1999) 'An investigation of text-based instructional materials enhanced with graphics', Educational Psychology, vol. 19, no. 3, pp. 323-335.

McQuarrie, E. and Mick, D. (1999) 'Visual rhetoric in advertising: Text-interpretive, experimental, and reader-response analyses', Journal of Consumer Research, vol. 26, no. 1, pp. 37-54.

McStay, A. (2013) Creativity and Advertising: Affect, Events and Process, London: Routledge.

McWilliam, E. (2008) 'Unlearning how to teach', Innovations in Education and Teaching International , vol. 45, no. 3, pp. 263-269.

Michael, J. (2006) 'Where's the evidence that active learning works?', Advances in Physiology Education, vol. 30, no. 4, pp. 159-167.

Mitchell, W. (1994) Picture theory, Chicago: University of Chicago Press.

Mitchell, W. (2002) 'Showing seeing: a critique of visual culture', Journal of Visual Culture, vol. 1, no. 2, pp. 165-181.

Paivio, A. (1971) Imagery and verbal processes, New York: Holt, Rinehart, and Winston.

Paivio, A. (2014) Mind and Its Evolution: A Dual Coding Theoretical Approach, Oxford: Psychology Press.

Prince, M. (2004) 'Does Active Learning Work? A Review of the Research', Journal of Engineering Education, vol. 93, no. 3, pp. 223-231.

Savery, J. (2006) 'Overview of Problem-based Learning: Definitions and Distinctions', The Interdisciplinary Journal of Problem-based Learning, vol. 1, no. 1, pp. 9-20.

Schrand, T. (2008) 'Tapping into active learning and multiple intelligences with interactive multimedia: a low-threshold classroom approach', College Teaching, vol. 56, no. 2, pp. 78-84.

Serig, D. (2006) 'A Conceptual Structure of Visual Metaphor', Studies in Art Education: A Journal of Issues and Research , vol. 47, no. 3, pp. 229-247.

Simpson, A. and Kaussler, B. (2009) 'IR Teaching Reloaded: Using Films and Simulations in the Teaching of International Relations', International Studies Perspectives, vol. 10, no. 4, pp. 413-427.

Sorden, S.D. (2013) 'Cognitive Theory of Multimedia Learning', in Irby, B., Brown , G. and Lara-Alecio, R. Handbook of Educational Theories, Charlotte: Information Age Publishing Inc.

Swimelar, S. (2013) 'Visualizing International Relations: Assessing Student Learning Through Film', Internationall Studies Perspectives, vol. 14, no. 1, pp. 14-38.

Thomas, E., Place, N. and Hillyard, C. (2008) 'Students and teachers learning to see Part 1: Using Visual Images in the College Classroom to Promote Students' Capacities and Skills', College Teaching, vol. 56, no. 1, pp. 23-27.

Thompson, C. (2003) PowerPoint makes you dumb, 14 December, [Online], Available:

http://www.nytimes.com/2003/12/14/magazine/14POWER.html?ex=1072414800\&en=1bb908537b $11 \mathrm{caad} \& \mathrm{ei}=5070$ [5 November 2015].

Tietje, L. and Cresap, S. (2005) Radical Pedagogy, [Online], Available:

http://www.radicalpedagogy.org/radicalpedagogy.org/Hegemonic Visualism.html [18 May 2015]. 
Torp, L. and Sage, S. (2002) Problems as possibilities: Problem-based learning for K-16 education, Alexandria, VA: Association for Supervision and Curriculum Development.

Trowler, V. (2010) Student engagement literature review, London: Higher Education Academy.

Tufte, E. (2015) The Work of Edward Tufte and Graphics Press, [Online], Available:

http://www.edwardtufte.com/bboard/q-and-a-fetch-msg?msg id=0003mW [5 August 2015].

Valeriano, B. (2013) 'Teaching Introduction to International Politics with Film', Journal of Political Science Education, vol. 9, no. 1, pp. 52-72.

Weber, C. (2001) 'The Highs and Lows of Teaching IR theory: Using Popular Films for Theoretical Critique', International Studies Perspectives, vol. 2, no. 3, pp. 281-287.

Weber, C. (2008) 'Popular visual language as global communication: the remediation of United', Review of International Studies, vol. 34, no. S1, pp. 137-153.

Weldes, J. (2003) 'Popular Culture, World Politics and Science Fiction', in To Seek Out New Worlds: Exploring Links Between Science Fiction and World Politics, New York: Palgrave.

Williams, V. (1998) Creating Effective Visual Metaphors, [Online], Available:

http://www.google.co.uk/url?sa=t\&rct=j\&q=\&esrc=s\&source=web\&cd=5\&ved=0CDUQFjAE\&url=htt p\%3A\%2F\%2Fwww.personal.psu.edu\%2Fstaff\%2Fv\%2Fq\%2Fvqw\%2FPortfolio\%2FVisIMeta.pdf\&ei=F xZiVe7IC8GsU9vhgfgG\&usg=AFQjCNFfV8D7xsu5KYjhTjsDKwkVHRYOw\&sig2=tqITHQIMMa anqDQfX5Lf [24 May 2015].

Winterbottom, M. (2016) Active Learning, 10 June, [Online], Available: www.cie.org.uk/images/271174-active-learning.pdf [10 June 2016]. 
'The Message Is The Medium': Evaluating The Use Of Images To Provoke Engagement And Active Learning In Politics and International Relations Lectures

Figure and Tables 
Figure 1 Desertification

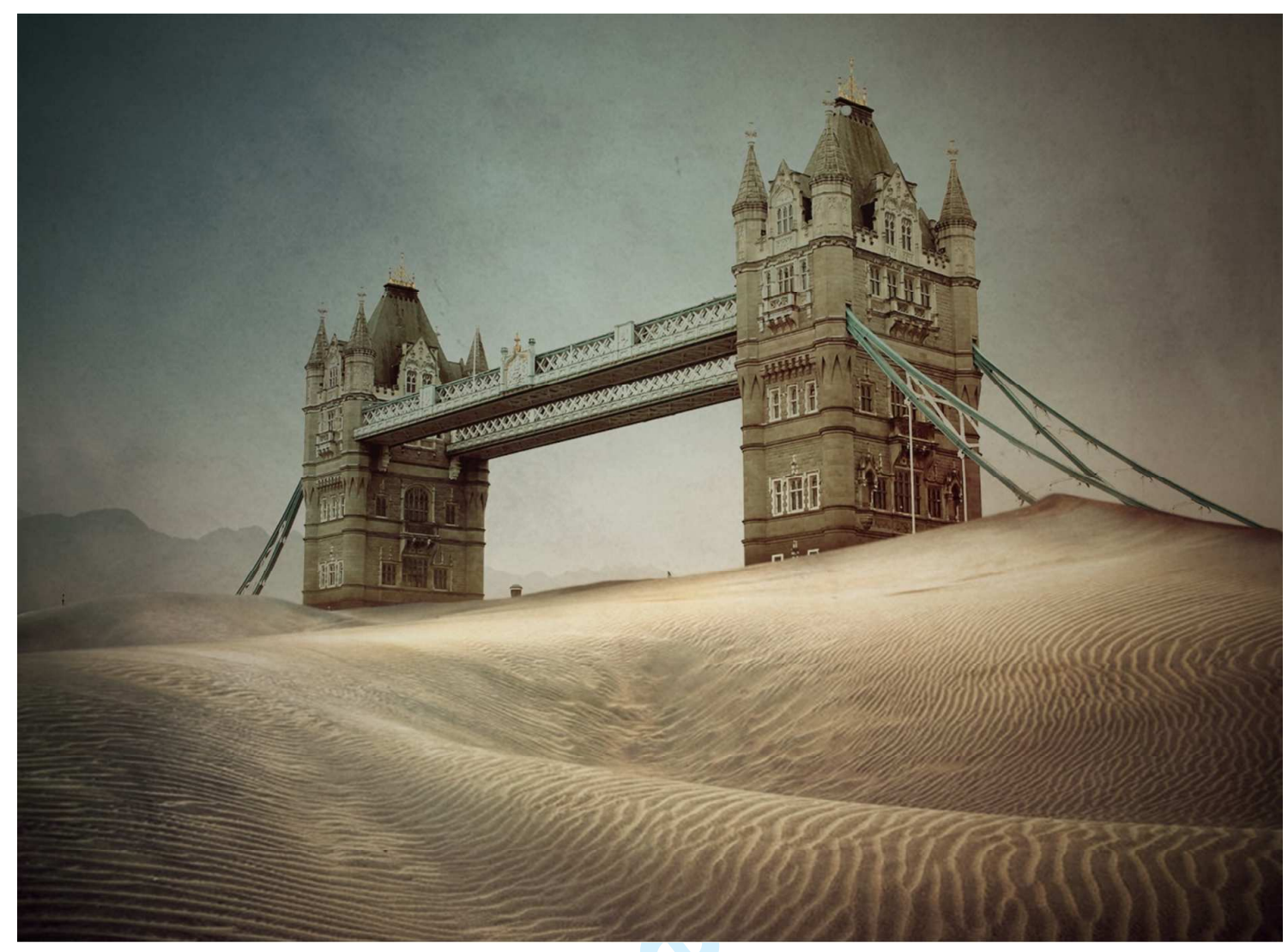




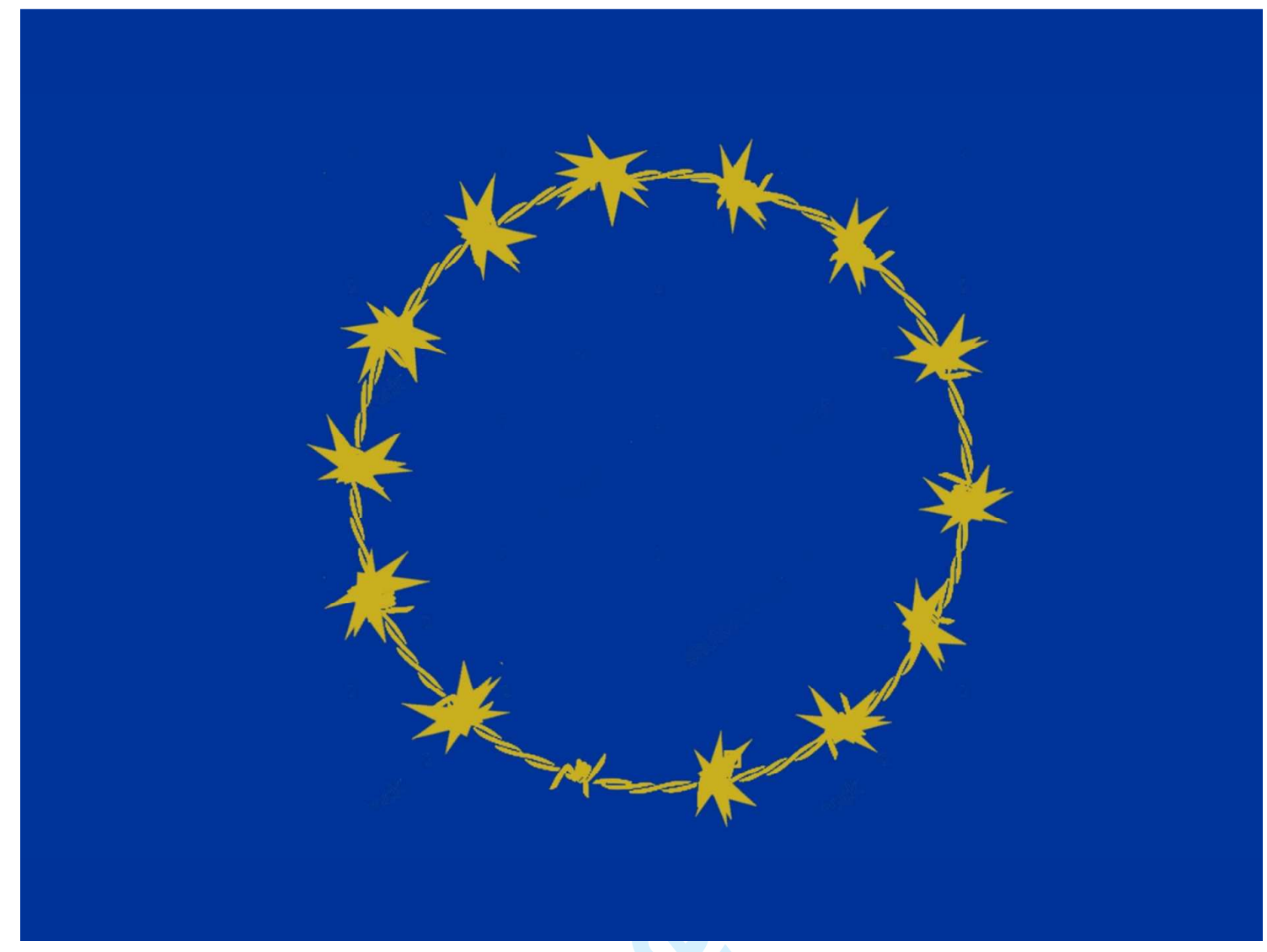

Figure 2 Europe barbed wire 


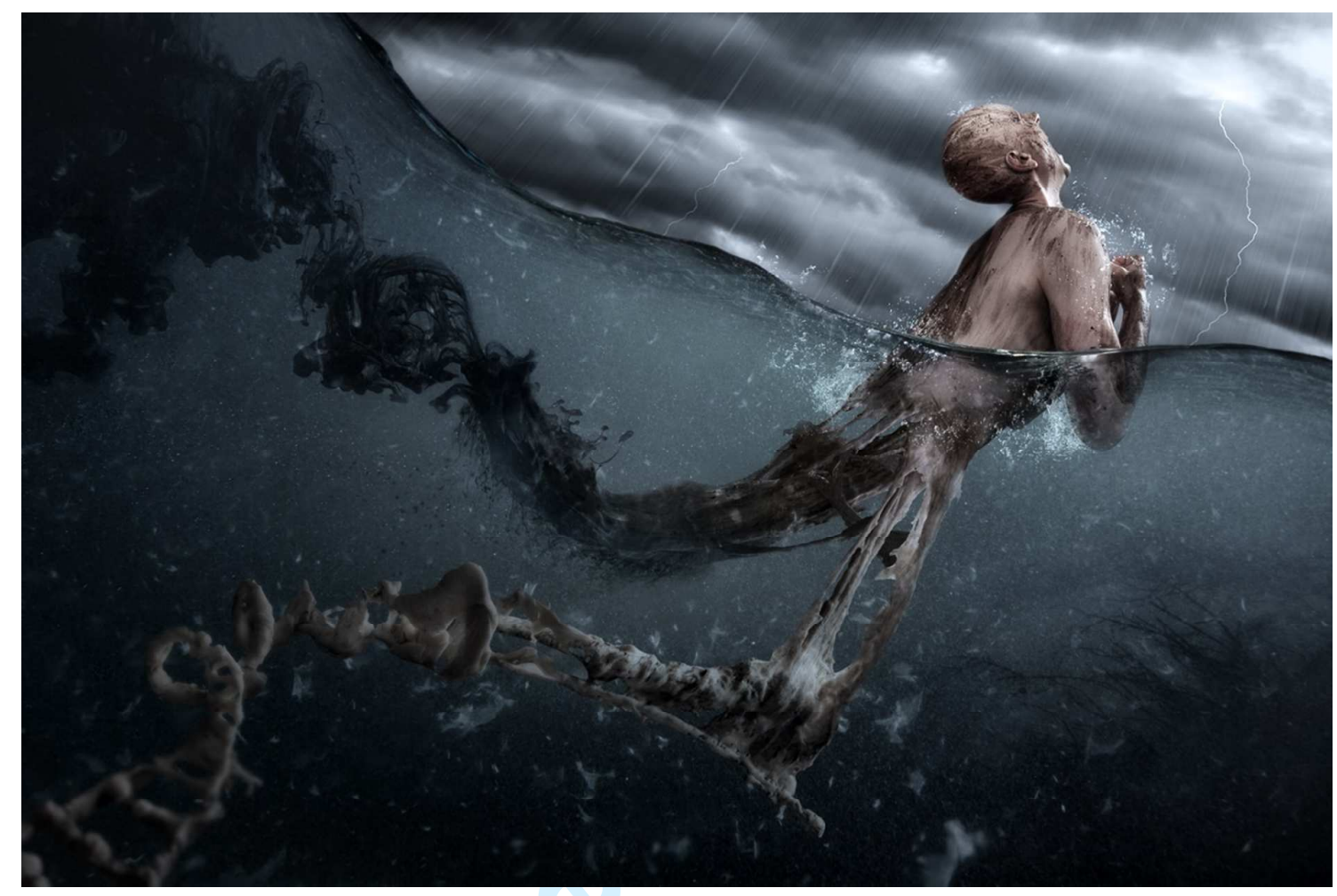

Figure 3 Evolution, by Kiciak, above 


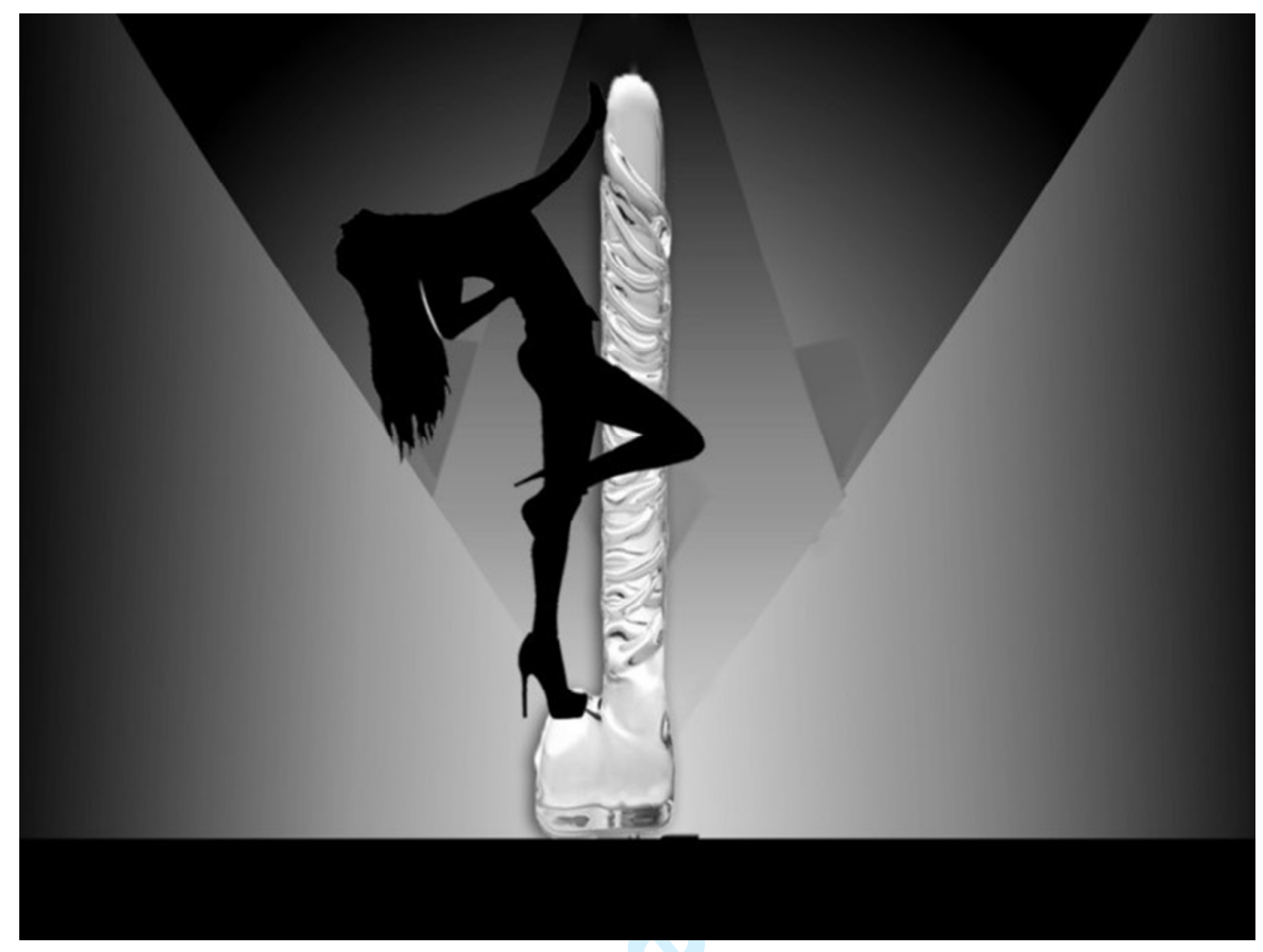

Figure 5 pole dancing 


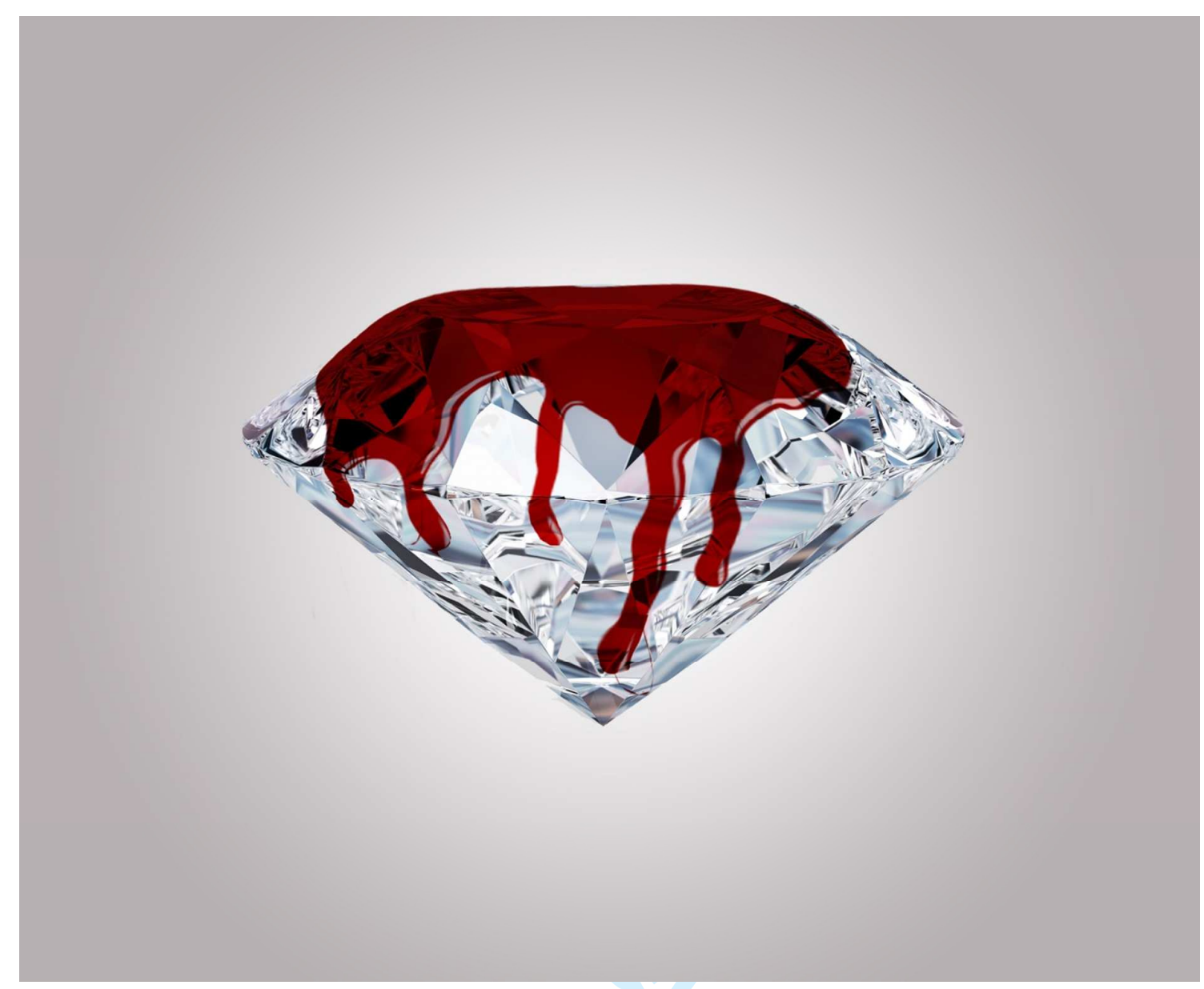

Figure 8 blood diamond 


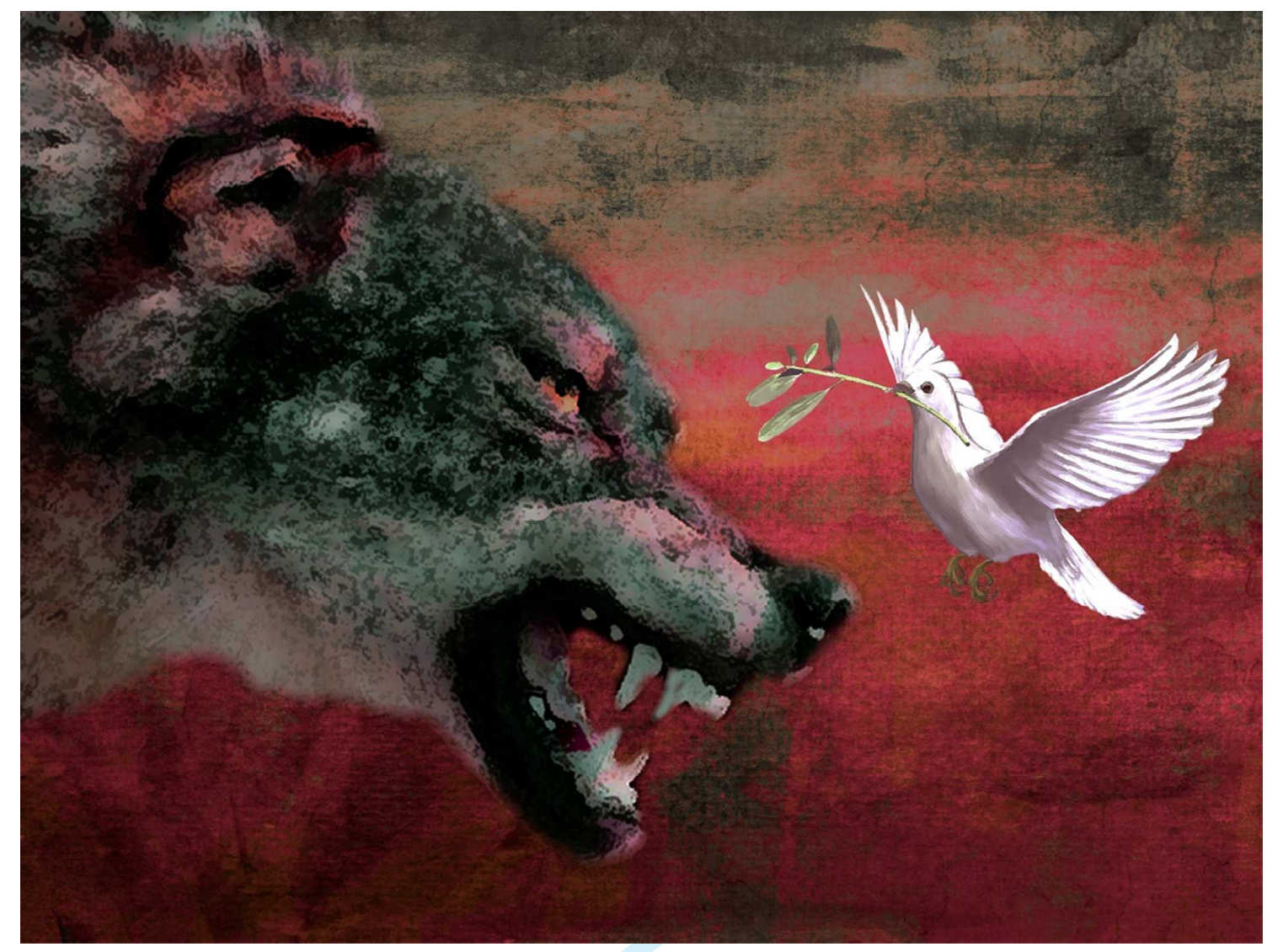

Figure 10 wolf and dove 
Table 1 Engagement aggregated 2014-2016 below

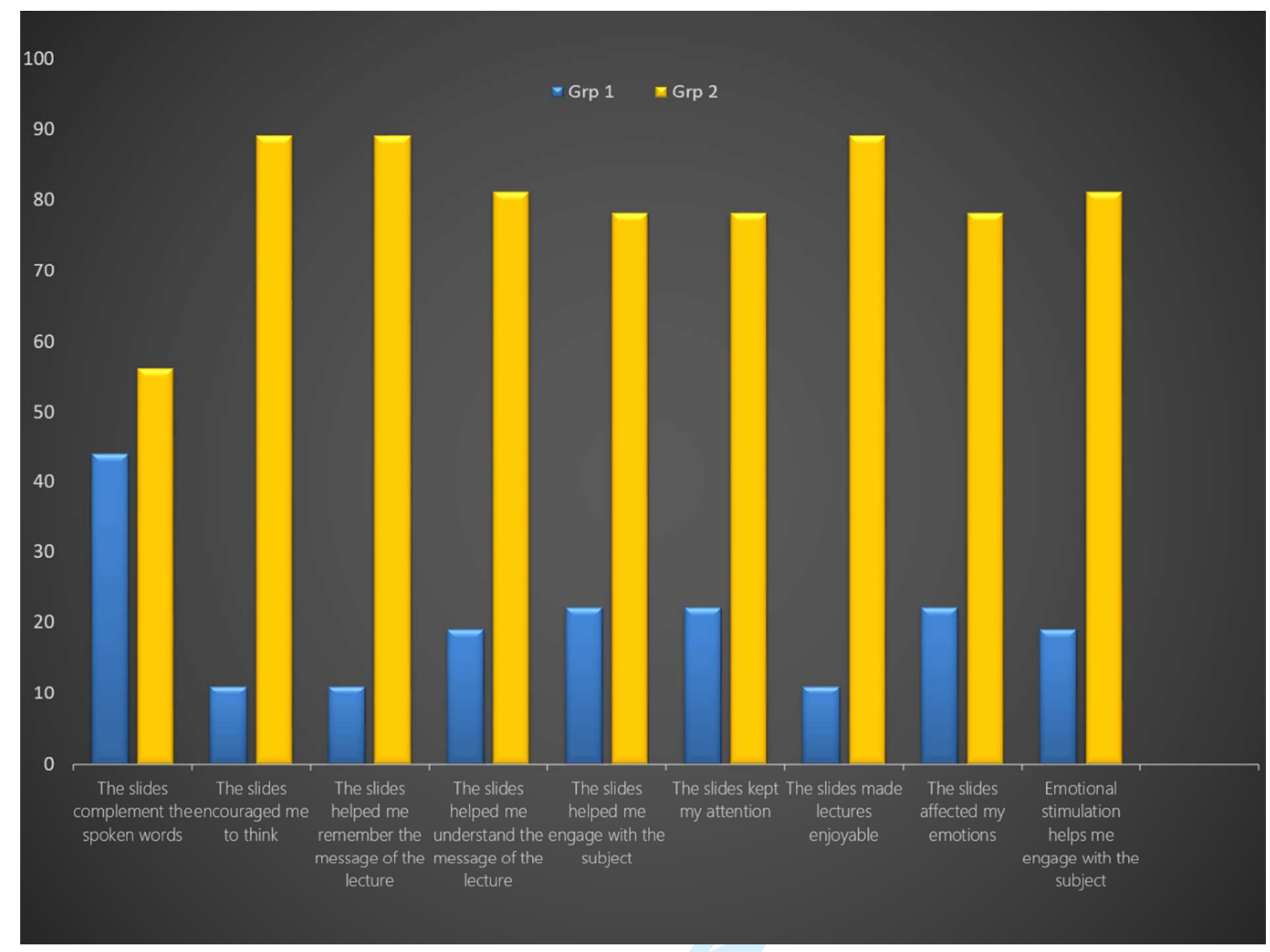


Table 2 Active Learning aggregated 2015-2016

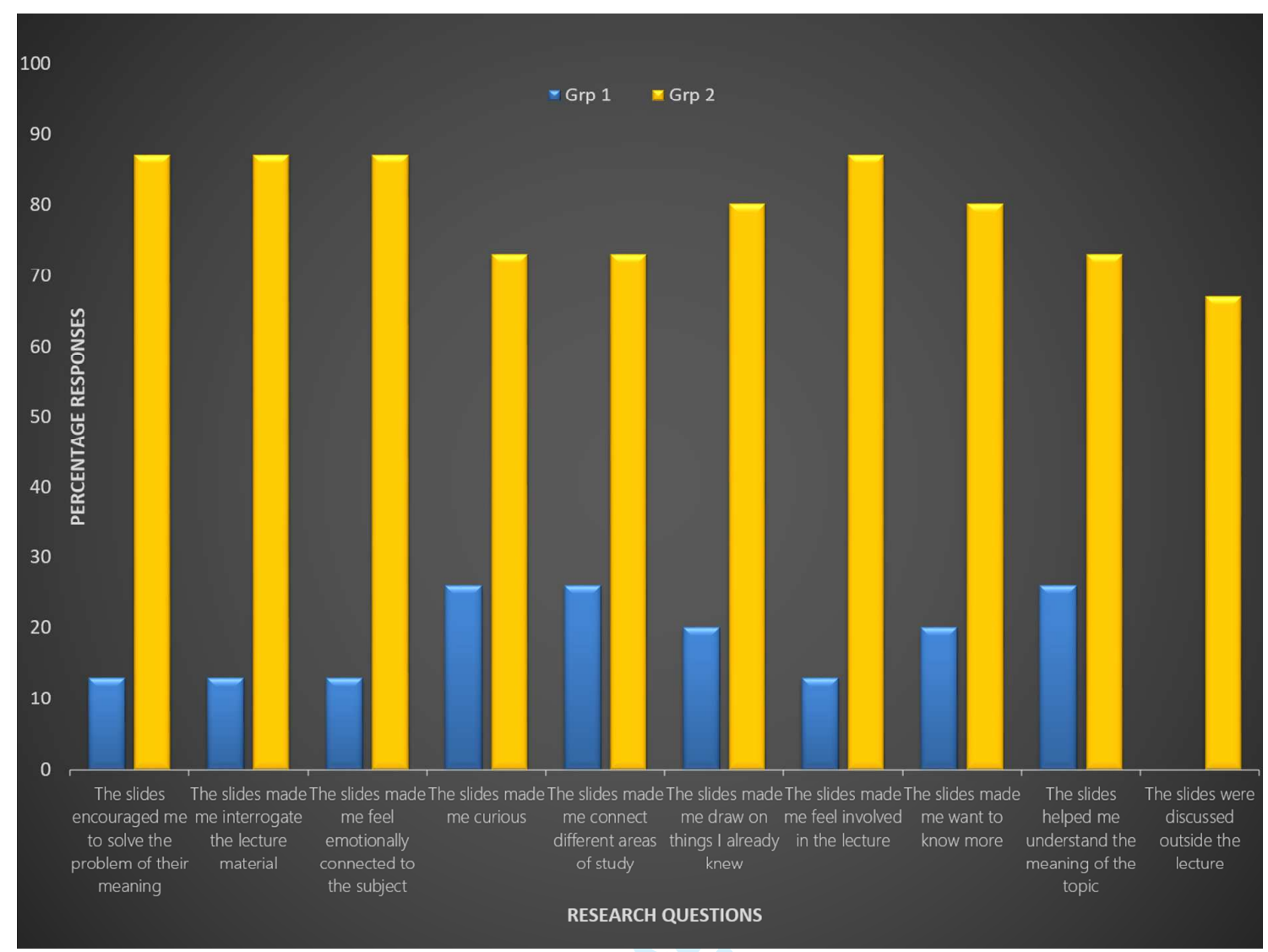

